\title{
Comment
}

\section{United States - Certain measures affecting imports of poultry from China: the fascinating case that wasn't}

\author{
JAN BOHANES* \\ Counsel, Advisory Centre on WTO Law, Geneva, Switzerland
}

\section{Introduction}

Professor Regan's paper on the US-Poultry (China) case provides highly interesting insight both into the facts of the case and the Panel's reasoning, as well as the broader systemic issues lurking behind them. The author has identified a number of thought-provoking aspects in a case that, at first glance, appears to be a relatively bland SPS dispute.

It is a pleasure and privilege to provide comments. I will address China's 'conditional' consultations request (II), the application of Articles 2.2 and 5.1 to Section 727 (III), Article 4 and 'equivalence' (IV), Article 5.5 and the 'appropriate level of protection' (V), and Article XX of the GATT 1994 (VI).

\section{China's 'conditional' consultations request}

With respect to China's 'conditional' consultations request, I agree with Professor Regan's characterization of the issue as 'the sort of tangle only lawyers can create', a tangle that to some might epitomize the less attractive, excessively legalistic side of WTO dispute settlement. ${ }^{1}$ However, I should like to add a further point to his analysis, a point that arguably explains why China phrased its consultations request in somewhat unusual 'conditional' terms. (Indeed, as I note below, other complainants have previously opted for the very same approach in at least two other disputes, although these disputes never reached the panel stage. Hence, China's approach was anything but outlandish.)

\footnotetext{
* The views set forth here are attributable to the author alone and are not those of the Advisory Centre. The author would like to thank Lukasz Gruszczynski and Don Regan, as well as other friends and colleagues, for valuable comments.

1 Professor Regan's article, Section 3.1.
} 
China's consultations request clearly reflects the wish to prioritize its GATT claims over any SPS claims. Indeed, China expressly stated in the consultations request that it did not consider Section 727 to be an SPS measure at all. But if China did not want to bring a case under the SPS Agreement, why would it 'conditionally' request consultations, and contemplate claims, under that Agreement? Why not leave these claims out of the consultations request altogether?

It is always risky to speculate on a party's motivations and thought processes, but a likely explanation is that China was concerned that, if the United States were to argue that Section 727 was an SPS measure and the Panel agreed, or if the Panel found on its own motion that Section 727 was an SPS measure, the Panel might consider that a challenge against Section 727 should have been brought under the SPS Agreement and not only under the GATT. Put differently, the question is: Where a complainant seeks to challenge an SPS measure (or what appears to be an SPS measure), does the complainant have a choice between bringing a challenge under the SPS Agreement (and maybe also under the GATT 1994) or bringing a challenge exclusively under the GATT 1994? Can a complainant choose not to challenge an SPS measure under the SPS Agreement at all and instead bring a claim under the GATT 1994 alone?

Before answering that particular question, it may be useful to pause and inquire why a complainant would want to choose to go under the GATT alone, rather than under the SPS Agreement (possibly combined with the GATT, in which case the Panel's analysis would, however, focus on the SPS Agreement as the more 'specific' agreement). One reason is that the choice between the SPS Agreement and the GATT 1994 makes a potentially big difference in the allocation of the burden of proof. If the measure is an import ban (as in the US-Poultry (China) case), a violation of Article XI of the GATT will be easily established and any scientific justification for the ban will have to occur under Article XX. Under Article XX, the burden of proof falls on the defendant - in this case, the United States. This might appear as an attractive proposition for the complainant. In contrast, under the SPS Agreement, it is the complainant that bears the burden of making a prima facie case of a lack of scientific justification under Articles 2.2 and 5.1. In this dispute, the burden of proof under the SPS Agreement was, of course, on China.

Of course, a complainant will not base its preference between the GATT and the SPS Agreement solely on the burden of proof. $^{2}$ There are other considerations, too. It is of course true that the SPS Agreement offers lines of attack against a measure that the GATT does not offer. A measure that is not supported by science, but is at the same time not discriminatory and not an import ban, will likely not violate the GATT - but it would violate the SPS Agreement. Similarly, blatant inconsistencies

2 Some might say that the significance of the allocation of the burden of proof is generally overstated in WTO dispute settlement. This is probably true, but it does remain of practical significance. 
between levels of protection may violate Article 5.5 of the SPS Agreement, but may not violate the GATT. In those situations, the SPS Agreement is, from the complainant's vantage point, 'superior' to the GATT. However, there will be other cases - for example those involving straightforward, unscientific import bans such as Section 727 that do not even look like an SPS measure at first glance - where a complainant might prefer a simple, lean case under the GATT, with a challenge under Article XI, rather than delving into the SPS Agreement. The requirement of scientific evidence-a very pertinent element for 'necessity' under Article XX (b) - will still remain relevant, but a violation will be established quickly under Article XI, and the onus will be on the defendant: in this case, to convince the Panel that what appears to be a budget measure actually has a health-protection purpose and, if so, is supported by scientific evidence.

China likely had these considerations in mind when it prioritized its GATT claim over any claim under the SPS Agreement. It is also useful to consider certain idiosyncrasies of the case - Section 727 was bound to expire and China may have been interested in establishing a general precedent, a 'slap on the finger' of the US Congress, as it were, rather than a complex and multilayered set of findings under the SPS Agreement. This all the more so as, for all China knew, any successor measures to Section 727 could look quite different than Section 727 (and indeed the successor measures did look different), such that complex and protracted litigation about Section 727 under numerous SPS provisions would have been of limited use for shaping US behaviour upon compliance.

But now we return to the above question - could China simply opt for the GATT, and not bring claims under the SPS Agreement, if Section 727 was an SPS measure? Does the SPS Agreement not only enable, but also oblige a complainant to challenge an SPS measure under the SPS Agreement? Is it a 'lex specialis'? Case law has not yet told us. ${ }^{3}$ The relationship between the various WTO agreements remains a thorny bundle of issues, with numerous sub-topics, whose depths the case law has only begun plumbing. ${ }^{4}$ There may be good arguments on both sides

3 What is clear from the case law is that, if both agreements are invoked, the legal analysis would start with the more specific agreement, that is the SPS Agreement. Appellate Body Report, United States - Final Countervailing Duty Determination with Respect to Certain Softwood Lumber from Canada, WT/DS257/ AB/R, adopted 17 February 2004, DSR 2004:II, 571, para. 134. The most recent statement of the above proposition was by the Panel in United States - Measures Concerning the Importation, Marketing and Sale of Tuna and Tuna Products, WT/DS381/R, circulated to WTO Members 15 September 2011 [adoption/ appeal pending], para. 7.40. This is precisely what the Panel did in this case.

4 One of the most salient sub-issues is, of course, the applicability of Article XX of the GATT to nonGATT agreements and provisions, an issue that has been subject to debate both in the case law and in academic debate. See Appellate Body Report in China-Measures Affecting Trading Rights and Distribution Services for Certain Publications and Audiovisual Entertainment Products, WT/DS363/AB/ R, adopted 19 January 2010, which applied Article XX to China's obligations in China's Protocol of Accession. Appellate Body Report, China-Publications and Audiovisual Products, paras. 205-233. See also Panel Reports, China-Measures Related to the Exportation of Various Raw Materials, WT/DS394/R and Corr.1, WT/DS395/R and Corr.1, WT/DS398/R and Corr.1, circulated to WTO Members 5 July 2011 
whether an SPS measure must be challenged under the SPS Agreement. However, from a litigator's perspective, the existing uncertainty requires carefully hedging one's bets and including claims under the SPS Agreement in the consultations request, even if the complainant still prefers to prioritize its GATT claims and would prefer not to raise any SPS claims at all. In the contrary case, it cannot be excluded that a panel would reject the case for jurisdictional reasons.

The layered wording of the Chinese consultation request, in my view, responds precisely to the uncertainty surrounding the relationship between the SPS Agreement and the GATT 1994, as well as China's wish to prioritize its GATT claims. The conditional nature of China's consultation request is therefore, in my view, more than just a quirk or infelicitous drafting. China's first choice was to pursue its case under the GATT. For that reason, China raised claims under the GATT and also argued that Section 727 was a budgetary measure, not an SPS measure. At the same time, for the reasons noted above, China had to provide for the contingency that the Panel found the measure to be an SPS measure and that, as an SPS measure, it had to be challenged under the SPS Agreement (with or without the GATT), rather than under the GATT alone. Hence China's conditional request under the SPS Agreement.

One can, of course, wonder about China's seemingly quick volte-face, and its decision to assert claims under the SPS Agreement, at the first oral hearing, once the United States argued that the measure at issue pursued a public-health objective. Of course, this decision does not necessarily shed much light on China's decision (from several months earlier) to write a conditional consultations request - China's assessment and strategy may have simply changed during those months. But even if we draw some indications from the 'volte-face', it is clearly a highly speculative exercise to decide what precisely China's later decision tells us. China may have considered that the goalposts had now changed because a public-health purpose had been asserted by the United States. Even if the United States did not claim outright that the measure was an SPS measure, there were good reasons to consider Section 727 to be an SPS measure. ${ }^{5}$ China may have thought that the Panel would examine that issue and that there was little prospect in convincing the Panel that the SPS Agreement did not apply. And, China may have reasoned, if the Panel were to take the view that SPS measures must be challenged under the SPS Agreement, China had to act quickly and file its SPS claims immediately, at the first oral

[appeal in progress], in which the Panel refused to apply Article XX to another provision in China's Protocol of Accession. Panel Reports, China-Raw Materials, para. 7.159.

5 In addition to the Panel's, as well as Professor Regan's convincing analysis as to why Section 727 was an SPS measure, see also the discussion in Lukasz Gruszczynski (2011), 'United States: Certain Measures Affecting Imports of Poultry from China-Just Another SPS Case?', 2:3 European Journal of Risk Regulation, 432, 435. Moreover, the definition of an SPS measure is to a large extent based on the healthprotection purpose of a measure, and once a defendant claims such a purpose, it becomes more difficult for a complainant to credibly assert the contrary. 
hearing - filing them later would have disqualified such claims. China could have admittedly put up a greater fight on this point, if it had felt strongly about avoiding the SPS Agreement. But perhaps it did not feel strongly, and it did not want to spend its credibility on an issue that did not matter all that much. China may also have changed its strategy and decided that findings of violation of the SPS Agreement were now desirable, after all. In any event, in an area as complex and under-interpreted as the relationship between the WTO agreements, it is quite difficult to look inside a complainant's head, as it were.

All in all, as convoluted as the 'conditional' approach in its consultations request may seem, China's strategy was understandable. Interestingly, China was anything but the first complainant to submit a 'conditional' consultations request under the SPS Agreement. There are at least three other disputes on the WTO docket where the complainant took the very same approach as China, namely WT/DS270, WT/ DS271, and WT/DS284, in which claims were worded as GATT claims and SPS claims appear only as conditional. These disputes never reached the panel stage, so China's approach merely happens to be the first one to become subject to a panel finding. ${ }^{6}$

The Panel's analysis and rejection of the United States' arguments is entirely correct. To some, the United States' objections may reflect what one would expect from a thorough and aggressive procedural defense. However, leaving aside its excessive formalism, the United States' view, if accepted, would lead to absurd results, as the Panel explained. The United States was undoubtedly aware of this and could not possibly expect to prevail. Specifically, the United States' approach would create two contradictory strands of case law, as the Panel noted. Under the first strand of case law, certain claims could be brought even if they were not mentioned at all in the consultations request (under the criteria set out in the Appellate Body Report in Mexico-Anti-Dumping Measures on Rice ${ }^{7}$ and repeated by the Panel Report in China-Publications and Audiovisual Products ${ }^{8}$ ); under the US-Poultry (China) strand of case law (as advocated by the United States) claims could not be brought even if they were expressly raised in the consultations request - simply because they were phrased 'conditionally'. This amounts, in my view, to unwarranted formalism that makes the life of complainants miserable for no obvious reason - in an adjudicative regime that is

6 See WT/DS270/1 and WT/DS271/1, which identify the SPS Agreement as a relevant agreement 'should Australia assert that the measure is an SPS measure'. In turn, WT/DS284/1 states that '[i]f the measures listed above are sanitary or phytosanitary measures as defined in the SPS Agreement, they would, in the view of Nicaragua, not be consistent with'.

7 Appellate Body Report, Mexico-Definitive Anti-Dumping Measures on Beef and Rice, Complaint with Respect to Rice, WT/DS295/AB/R, adopted 20 December 2005, DSR 2005:XXII, 10853, para. 138.

8 Panel Report, China-Measures Affecting Trading Rights and Distribution Services for Certain Publications and Audiovisual Entertainment Products, WT/DS363/R and Corr.1, adopted 19 January 2010, as modified by Appellate Body Report, WT/DS363/AB/R, para. 7.115. 
already, by its very procedural design and its remedies, not excessively complainant-friendly. ${ }^{9}$

Finally, there may be yet another reason why admitting the 'conditional' nature of China's consultation request as sufficient under Article 4 of the DSU is necessary and important. Appellate Body case law from the more recent past has given rise to certain (arguably unfortunate) requirements on the complainant to 'raise' or 'mention' certain provisions of the covered agreements, even if the burden of proof under these provisions properly rests on the defendant. One such example is the Enabling Clause. The Appellate Body has stated that, where a complainant 'would have been well aware that the [measure] must comply with the requirements of the Enabling Clause, and that the [defendant] was likely to invoke the Enabling Clause in response to a challenge of inconsistency with Article I', the complainant must allege the inconsistency with the Enabling Clause. ${ }^{10}$ As a result of this (utterly curious) finding, the burden of proof under the Enabling Clause remains on the defendant, but the complainant must, as it were, anticipate that the defendant might rely on this defense. The complainant must therefore 'raise' the Enabling Clause and argue that the conditions of this defense have not been complied with-without knowing whether the defendant will actually rely on this provision. These 'conditional' claims and arguments by the complainant, one would assume, must be contained in the consultations and panel requests in order to be properly before the Panel.

A similar example is the Appellate Body's decision on Article II of the GATT 1994 in the India-Additional Import Duties dispute. According to this ruling, a complainant arguing a violation of Article II:1(b) must, depending on the circumstances, also raise arguments and evidence that the provision is not justified under Article II:2(a). This is a provision on which the defendant presumably may or may not rely-it certainly is unknown at the time the complainant submits its consultations request. ${ }^{11}$

One can easily question the wisdom of this case law. ${ }^{12}$ However, whatever its merits, given that this case law exists and given that it positively requires the

9 Perhaps the one thing that China could have done differently would have been not to attach the condition to the statement that it requested consultations with the United States. It could have instead stated that it was requesting consultations with the United States on a certain measure, namely Section 727; it then could have alleged that 'this measure is inconsistent with Article XI of the GATT and, if the United States were to argue that it is an SPS measure, also with the SPS Agreement'. (This is what complainants in other disputes have done, see footnote 6.) But are we going to make the admissibility of a consultations request, and a panel's jurisdiction, depend on formal aspects of this kind?

10 Appellate Body Report, European Communities - Conditions for the Granting of Tariff Preferences to Developing Countries, WT/DS246/AB/R, adopted 20 April 2004, DSR 2004:III, 925, para. 117ff. (emphasis added).

11 Appellate Body Report, India - Additional and Extra-Additional Duties on Imports from the United States, WT/DS360/AB/R, adopted 17 November 2008, para. 190.

12 Arguably, this case law (especially the India-Additional Import Duties variant) injects unnecessary uncertainty and unpredictability into a complainant's life, and this uncertainty and unpredictability outweighs any concerns that may have led the Appellate Body to adopt this approach. 
complainant to raise arguments 'just in case' the defendant will subsequently rely on them, it seems hardly an excessive concession towards the complainant to actually permit a conditional clause in the consultations request (as well as in panel requests, for that matter).

\section{The application of Articles 2.2 and 5.1 to measures such as Section 727}

Professor Regan makes an interesting and plausible argument that scientific evidence and risk assessment underpinning a country-specific measure, such as Section 727, is different from the risk assessment and scientific evidence that underlies non-origins specific measures. Typically, he says, scientific evidence and risk assessment concern more generic questions about human or animal virology, statistics, and epidemiology. As a result, he wonders whether Articles 2.2 and 5.1 'arguably should not be thought to require the same sort of justification for Section 727 that they require for the measures that have given rise to previous SPS cases', because " "[s]cientific justification" is simply not possible for a measure like Section 727 , if by "science" we mean laboratory methods, or extra-laboratory controlled experiments, or even broader epidemiological and statistical techniques' for investigating 'general questions about nature.'13 Professor Regan nevertheless also accepts that the evidence underpinning a country-specific measure like Section 727 deserves to be qualified as scientific if one adopts a broader understanding of science, namely, as 'a process characterized by systematic, disciplined and objective enquiry and analysis, that is, a mode of studying and sorting out facts and opinions' ${ }^{14}$

The distinction between country-specific measures such as Section 727 and more origin-neutral measures is certainly very relevant. A risk assessment underlying Section 727, which relates to how China operates its poultry sanitary regime, cannot be as generic and abstract as statements about, say, the likelihood that consuming substance $X$ over a period of $Y$ years entails a 1:10,000 probability of causing cancer. From a litigant's perspective, the distinction drawn between the different types of risk assessment is most pertinent, because it makes clear that the evidence to be gathered for a dispute will be quite different. A challenge to Section 727 should (at least conceptually) involve country-specific evidence on how China enforces its laws and regulations, including the relevant sanitary inspection procedures and other 'operational' aspects, and, in the light of these specific conditions in China, how likely poultry exported from China is likely to give rise to human health threats in the United States. Such evidence is of course different from, for instance, the type of evidence that was at issue in the EC-Hormones dispute

13 Professor Regan's paper, Section 4.

14 Professor Regan's paper, Section 4. 
about the general, non-country-specific risks of consumption of hormone-treated beef.

At the same time, this distinction would not, in my view, substantially affect the applicability of Articles 2.2 and 5.1. The term 'risk assessment' is arguably broad enough to encompass all of these different scenarios. A risk assessment within the meaning of Article 5.1 can be either of a more generic, abstract type ('does substance $\mathrm{X}$ generate cancer and, if so, under what conditions?'), or of a more specific nature ('how risky is poultry exported from China, given the actual sanitary circumstances and the manner of administration of Chinese laws 'on the ground"?). There are several good arguments to read the concept of 'risk assessment' sufficiently broadly to capture both types of inquiries. A risk assessment shall serve as the basis for SPS legislation as 'appropriate to the circumstances', ${ }^{15}$ which arguably suggests a degree of flexibility in the concept of 'risk assessment'. Indeed, the Appellate Body has ruled early on that a risk assessment must go beyond the laboratory setting and take into account 'the real world, where people live and work and die'. ${ }^{16}$ Looking beyond WTO legal texts, the meaning that the Codex Alimentarius gives to the term 'risk assessment' also appears sufficiently broad to encompass matters beyond the laboratory setting, including the level of sanitation and process controls, handling and packaging by commercial actors, and similar non-laboratory issues. ${ }^{17}$ As a result, even accepting that what counts as risk assessment for a country-specific measure will be different from what constitutes a risk assessment for a general, origin-neutral measure, this does not, in my view, mean that the standard under Articles 2.2 and 5.1 should be fundamentally different or less exacting when applied to a measure such as Section 727.

Indeed, even international standards can be country-specific and processorientated. International standards occasionally pertain to detailed operational aspects of a health regime, including inspection procedures. ${ }^{18}$ There are also international standards pertaining to individual countries, or regions thereof. A good example is determinations by the World Organisation for Animal Health

15 See Article 5.1 of the SPS Agreement.

16 Appellate Body Report, EC-Measures Concerning Meat and Meat Products (Hormones), WT/DS26/AB/R, WT/DS48/AB/R, adopted 13 February 1998, DSR 1998:I, 135, para. 187.

17 See for instance the Codex Alimentarius Commission's Principles and Guidelines for the Conduct of Microbiological Risk Assessment, CAC/GL-30 (1999), p. 4, which states: 'Factors that must be considered for Exposure Assessment include the frequency of contamination of foods by the pathogenic agent and its level in those foods over time. For example, these factors are influenced by the characteristics of the pathogenic agent, the microbiological ecology of the food, the initial contamination of the raw material including considerations of regional differences and seasonality of production, the level of sanitation and process controls, the methods of processing, packaging, distribution and storage of the foods, as well as any preparation steps such as cooking and holding.' See www.fao.org/docrep/005/y1579e/y1579e05.htm (last visited 9 November 2011).

18 As an example, see for instance the Codex Alimentarius Code of Hygienic Practice for Milk and Milk Products or Code of Hygienic Practice for Meat, Food and Agriculture Organization. 
(the former Office International des Epizooties) that categorize countries and subnational regions into different categories depending on how prevalent a particular animal disease is in that country and what relevant animal husbandry practices that country applies (e.g. vaccination). This categorization may also come with recommendations about suitable measures to be imposed by importing countries on products from the various categories of regions. These are precisely the standards that are relevant for the 'regionalization' requirement in Article 6 of the SPS Agreement. ${ }^{19}$ Of course, there always remains the question whether actual administrative practice in a particular country effectively applies rules and procedures enshrined in national legislation or in an international standard - which may be a determination that the importing country may have to do for itself (and often does, by means of bilateral verification visits). All in all, Articles 2 and 5, with their scientific evidence and risk requirement and the principled obligation to use international standards where available, in my view remain fully applicable to country-specific measures such as Section 727.

In any event, whatever the proper reading of 'risk assessment', it is unlikely that in the US-Poultry (China) dispute there was much to gain for the United States by emphasizing that the required evidence, for purposes of Articles 2.2 and 5.1, was different from previous SPS disputes. The key problem for the United States was that it had no sufficiently strong poultry-specific evidence that would support Section 727. What is more, the United States faced an additional problem in that the Food Safety and Inspection Service ('FSIS') had conducted an investigation/ audit conducted by its own agency and had made positive determinations of the Chinese poultry regime. ${ }^{20}$ It appears that all subsequent evidence favourable to the United States' defensive stance - for instance, critical reports of China's hygiene standards in the food sector, in the media and by international organizations - was generic and not poultry-specific. The United States seems to have considered that, whatever other evidence existed, it would not sufficiently substantiate Section 727 and/or 'override' the previous positive assessment by the FSIS. If that was the United States' view of its position, it is understandable that it simply threw up its hands under Article 5.121 and did not put up much of a serious fight under

19 As an example, see the standards/assessments promulgated by the World Organisation for Animal Health with respect to foot and mouth disease, http:/www.oie.int/animal-health-in-the-world/officialdisease-status/fmd/ (last visited 9 November 2011).

20 The FSIS concluded, based on its previous on-site audit, that China's poultry-inspection system was equivalent to that of the United States for processed foreign poultry products. The FSIS published notification in the Federal Register that it would be adding China to the list of countries eligible to export processed poultry products not slaughtered in China. The FSIS, again based on a previous on-site audit, had also made a preliminary decision finding China's inspection system for domestically slaughtered poultry products equivalent to that of the United States. US congressional legislation then precluded any further steps in these procedures through a series of budgetary measures, of which Section 727 was one.

21 Panel Report, US-Poultry (China), para. 7.185. 
Article 2.2, either. ${ }^{22}$ Finally, as Professor Regan points out, the United States was also disinclined, for systemic reasons, to argue for lower standards under Article 2.2 and 5.1. All this, in my view, explains the United States' lack of enthusiasm in defending Section 727 - leaving aside the additional helpful fact that the measure, in any event, had expired during the early stages of the panel process.

\section{Article 4 and 'equivalence'}

Prof. Regan's reflections on Article 4 and the United States' 'equivalence' regime are very insightful and I am in full agreement. Like him, I believe that it is highly unlikely that Article 4 was intended to apply to the exclusion of all other provisions of the SPS Agreement, for the reasons stated by the Panel. The systemic implications for the SPS Agreement would be detrimental and utterly unwarranted. One can criticize aspects of the Panel's interpretative approach, ${ }^{23}$ but the result is certainly correct. I strongly doubt that the United States' lawyers thought for a minute that they would prevail with this argument.

Furthermore, the distinction between 'facilitative' and 'exclusionary' regime is a very useful conceptual tool. Like Professor Regan, I find it more likely that the SPS Agreement envisages the former type of 'equivalence' under Article 4. This question would, of course, be of the utmost systemic importance if indeed, as the United States argued, Article 4 applied to the exclusion of all other provisions of the SPS Agreement. In that case, a Member could adopt a 'banned until proven safe' (exclusionary) regime as that embodied in the Poultry Products Inspection Act (PPIA), based on country-wide equivalence, and thereby escape all strictures of the SPS Agreement other than the very permissively worded Article 4. However, since Article 4 does not apply in isolation, as the Panel rightly found, the stakes are somewhat lower.

But, precisely, this is not the end of the interesting story here. The issue goes beyond the scope of application of Article 4 of the SPS Agreement and beyond the question of what type of equivalence regimes Article 4 contemplates. The distinction between 'facilitative' and 'exclusionary' regime echoes, to some extent, the interesting relationship between a significant number of (exclusionary) SPS/quarantine regimes and the strict letter of the entire SPS Agreement. In principle, any SPS measure affecting trade must be either based on scientific evidence and a risk assessment, or must at least satisfy the criteria under Article 5.7 as a provisional health measure. However, many WTO Members operate

22 Ibid., paras. 7.195-7.196.

23 See for instance Lukasz Gruszczynski, who argues that the Panel should have explained more thoroughly the interpretative significance of the Decision on the Implementation of Article 4 of the Agreement on the Application of Sanitary and Phytosanitary Measures for construing Article 4. Lukasz Gruszczynski (2011), 'United States: Certain Measures Affecting Imports of Poultry from China-Just Another SPS Case?', 2:3 European Journal of Risk Regulation, 431, 436. 
'banned until proven safe' (exclusionary) SPS/quarantine regimes. Under these regimes, products are a priori excluded, for purposes of protecting public health and safety, until the importer has gone through an administrative procedure and has demonstrated that its particular product is safe. Upon successful completion of the authorization procedure, importation/marketing can begin. Section 727 and the Poultry Products Inspection Act (PPIA) are an example of such measures applied on a country-wide basis. Other existing import regimes apply this principle on a product-specific or exporter-specific basis. ${ }^{24}$ Professor Regan provides another hypothetical example of such a regime, operating on an exporter-specific basis. ${ }^{25}$

It is not immediately clear where such regimes fit under the SPS Agreement. Can these regimes be considered to be 'based on a risk assessment', as this requirement has been read by the Appellate Body? Case law requires that a risk assessment be sufficiently specific to the risk (and the product) at issue. This suggests that the regulator is banning or otherwise restricting a product because it knows there is something (potentially) wrong with it. The rationale behind the banning of a product until proven 'safe' by the prospective producer/seller is precisely the reverse - the regulator feels that it does not know enough about the product, but is concerned that something might be wrong with it. Of course, as a matter of general policy, it can make perfect sense to prohibit market participants to import and market products (including food) as they please, without previous authorization by the national authorities. This is also why so many WTO Members have so many of these 'exclusionary' sanitary and quarantine regimes. However, it does require an at least somewhat expansive reading of the text of the SPS Agreement to bring such a regime within the fold. Indeed, there is an instance in which a WTO Member submitted a consultations request implying a challenge to an SPS/quarantine regime as a whole, on the ground that 'import of products is a priori prohibited, although there is no risk assessment' (the case was later settled). ${ }^{26}$

One option to fit such regimes under the SPS Agreement is, of course, to read the notion of risk assessment under Article 5.1 very broadly and generally. Under this approach, a product-specific or risk-specific assessment would not be required. ${ }^{27}$ This could be done by relying on the 'as appropriate to the circumstances' language in Article 5.1. At first, this sits uncomfortably with existing case law on this provision, including the requirement that a risk assessment be sufficiently specific. However, the non-product-specific and non-risk-specific/multi-risk nature of

24 By way of examples, consider the EU's GMO regime as well as the EU's Novel Foods regime; the Australian quarantine regime for products such as fruits and vegetables; and, of course, the United States' very own PPIA.

25 Professor Regan's article, Section 7.

26 See WT/DS287/1, consultations request by the EU against Australia. See also WT/DS270/1 and WT/ DS271/1, consultation requests filed by the Philippines against Australia, which are less explicit than the EU request, but nevertheless also appear to challenge, inter alia, the Australian quarantine regime as such.

27 I am grateful for a thought-provoking discussion of these questions with my colleague Hunter Nottage. 
blanket quarantine regimes might justify requiring only a very generic, non-product specific and non-risk specific 'risk' assessment (a sort of 'parallelism', as it were). For instance, it might be enough to point to the obvious and widely accepted fact that foods can carry pathogens, can therefore cause pests, diseases, and allergies, and such risks are on average exacerbated if, for example, fresh fruits and vegetables from overseas (with different ecological systems) are introduced without prior governmental approval. Admittedly, this carries a hint of the 'theoretical' risk that the Appellate Body rejected in EC-Hormones, but it might just do the trick. ${ }^{28}$

Alternatively, one could attempt recourse to Article 5.7, where the evidentiary requirements on scientific justification are lower than under Article 5.1. However, other circumstances are required under Article 5.7 - for instance, the insufficiency of scientific evidence to perform a risk assessment, the provisional nature of such measures, and the seeking of additional evidence. One could try to stretch Article 5.7 sufficiently wide to bring the 'exclusionary' regimes within the fold, but problems remain. For instance, the requirement on Members to seek additional evidence and periodically review the situation may not allow a Member to simply sit back and wait for exporters to request authorization for their products, as is the case under some (probably most of) the 'exclusionary' quarantine regimes. ${ }^{29}$

The reason why this legal issue remains unresolved and such regimes have not been challenged is their widespread use and the concomitant political sensitivity. Members are happy not to throw stones in their own glass house. Moreover, most commercial actors are probably also willing to live with such regimes, as long as they operate reasonably and objectively. Even if such a dispute went to adjudication, the Panel would no doubt be influenced by the widespread use of such blanket 'banned until proven safe' quarantine regimes-ruling them inconsistent under the SPS Agreement would be so problematic that a panel would probably be instinctively predisposed to stretch the SPS Agreement just enough to avoid a ruling of inconsistency.

\section{Article 5.5 and the 'appropriate level of protection'}

Professor Regan's central point with respect to the 'appropriate level of protection' ('ALOP') is that 'the Panel should have found that the United States' ALOP, even with regard to China, was simply "safe", if the United States could have plausibly claimed that it was entitled to believe that Section 727 was necessary to achieve the same level of protection as required for other supplier countries. Professor Regan

28 Appellate Body Report, EC Measures Concerning Meat and Meat Products (Hormones), WT/DS26/ AB/R, WT/DS48/AB/R, adopted 13 February 1998, DSR 1998:I, 135, para. 186.

29 Perhaps one could make the argument that until either some other Member or at least a foreign producer asks for authorization, there is no way for the importing Member to know that it is restricting trade in that specific product. I am indebted for this idea to Professor Don Regan. 
argues that different measures - including different country-specific measures - may be necessary to achieve the same level of protection. The Panel should also not have shifted the burden of proof to the United States to justify Section 727. He subsequently makes a few critical points also with respect to the Panel's analysis under Article 5.5.

I agree with several points of that analysis. It is no doubt true that a WTO Member can impose different measures with respect to different supplier countries all the while pursuing the same 'level of protection'. This is straightforward - by the same token, for instance, formally different treatment of domestic and foreign service providers can result in substantively the same treatment, as Article XVII: 2 of the GATS expressly states. A practical example in the SPS context is one I have described earlier, namely where an animal disease is less prevalent in some countries (or regions) than in others and where countries practice different animalhusbandry practices (for instance, vaccination). Faced with such different circumstances across different supplier countries, WTO Members could impose different measures on products depending on where these products come from - for instance, limiting importation only to animals of a certain age, only to certain parts of animals, only to animal products that have been treated in a particular manner, etc. Indeed, a number of such import restrictions may find direct justification in determinations or standards promulgated by, for instance, the World Organisation for Animal Health. These measures could, despite their differences, all reflect the very same 'level of protection', because the levels of risk vary from country to country and from region to region.

Moreover, regardless of whether there are differences in level of protection or not, the burden of proof under Article 5.5 should not shift from the complainant to the United States simply because the measure at issue is country-specific. The existence of different levels of protection must be demonstrated by the complainant. I therefore agree with Professor Regan's criticism of the Panel's oblique statements on the burden of proof. The Panel stated that:

to prove that such substantially different measures were needed to achieve the same ALOP, the United States would have to demonstrate that poultry products from China presented a greater risk than poultry products from other WTO Members. ${ }^{30}$

This is an unfortunately cavalier description of the burden of proof. At the same time, I do not read the Panel as having effectively reversed the burden of proof. The full context reveals that the Panel had previously determined that Section 727, applicable only to China, had created a higher level of protection than measures imposed on other supplier countries. And this was not only because the United States was applying 'substantially different measures' or because Section 727 was 
country-specific, as Professor Regan points out. The Panel's finding arguably went beyond that. The Panel had noted that 'the regular FSIS procedures prohibit importation of poultry products from a particular country only until that country has demonstrated that its SPS measures can achieve the ALOP expressed in the PPIA. However, the effect of Section 727 was to prohibit the importation of poultry from China in any instance, regardless of whether China demonstrated that its own SPS measures could achieve the ALOP expressed in the PPIA.'31 This means that, while all countries but China had 'at least... an avenue... to gain access to the United States market', no such avenue was available for Chinese poultry products. ${ }^{32}$ Hence, in this particular instance, different measures resulted, at least prima facie, in substantively different levels of protection. What the Panel should have said was that the complainant had made out a prima facie case and that the United States could now attempt to rebut this prima facie case by showing that risk from Chinese poultry products was higher.

Finally, Professor Regan raises a most relevant point about how 'arbitrariness' of, and lack of 'justification' for, differences between levels of protection should be demonstrated for purposes of Article 5.5 and how the Panel proceeded in this regard. In a nutshell, the Panel examined whether there was scientific justification for the different levels of protection and concluded there was none. Specifically, there was no risk assessment in support of Section 727 - the same reason for which the Panel had found a violation of Article 5.1. As a result, the Panel concluded, the difference in the levels of protection was 'arbitrary' or 'unjustifiable'. ${ }^{33}$ Professor Regan's criticism is that the Panel excessively focused on science as a litmus test for examining 'arbitrariness' or 'unjustifiability' under Article 5.5. By doing so, the Panel disregarded the purpose of Article 5.5, which is to identify a type of violation that can exist even when a risk assessment exists and supports the more protective measure.

This criticism is entirely correct. It is worth quoting fully the Panel's (unfortunate) relevant statement on this point:

we are of the view that the scientific support, or lack thereof, for the difference between the ALOPs the measures seek to achieve should have a bearing on an analysis of whether such a difference is arbitrary or unjustifiable under Article 5.5 of the SPS Agreement. Indeed, in the context of Article 5.5 to show that the distinction in ALOPs is not arbitrary or unjustifiable, a Member must demonstrate that there are differing levels of risk between the comparable situations. We are of the view that such a demonstration requires scientific evidence.

31 Ibid., para. 7.249 .

32 Ibid.

33 Ibid., para. 7.263 . 
Several things are problematic with this statement, but let us focus on the 'scientific evidence' requirement. ${ }^{34}$ This goes to the question of how to assess 'arbitrariness' and 'unjustifiability', which has not been systematically addressed by the Appellate Body. Professor Regan rightly criticizes the Panel on this point.

The issue is how significant scientific evidence should be for determining whether differences between levels of protection are 'arbitrary' or 'unjustifiable'. The Panel transferred previous case law on Article 2.3 and Article XX of the GATT 1994 into Article 5.5 and found that 'arbitrariness' and 'unjustifiability' would be determined in relation to the cause of the difference in levels of protection. ${ }^{35}$

That is not in itself an objectionable approach - even if it is not clear why 'cause' should be the exclusive criterion for arbitrariness and why, for instance, the extent of the difference between levels of protection should not also play a role. It is also perfectly correct, as the Panel stated, that scientific evidence can have a bearing on whether differences between levels of protection are 'arbitrary' or 'unjustifiable'. The absence of scientific support for one of the measures, as in the US-Poultry (China) case, can be highly indicative of 'arbitrariness' and 'unjustifiability'. The difference in the level of protection in this case was pronounced-China was banned from exporting under any circumstances, whereas all other countries had a chance of demonstrating equivalence - and there was no scientific justification for the extra protection applied to China (scientific evidence actually pointed in the opposite direction).

34 In addition, I see two other problems. First, there is (yet another) misleading statement on the burden of proof-clearly, a defending Member does not (initially) have to demonstrate anything, because the burden of proof is on the complainant. The panel finding should probably be viewed again in the specific context of this case, where there was no scientific justification for Section 727, which to the Panel apparently amounted to a prima facie case, such that the burden of proof shifted to the United States.

Second, the statement that what should be demonstrated is that there are differing 'levels of risk' seems, strictly speaking, incorrect. What matters under Article 5.5 is whether (1) there are different 'levels of protection' (something conceptually different from the 'level of risk'), (2) whether the difference between the levels of protection is 'arbitrary' or 'unjustifiable', and (3) whether, as a consequence of (1) and (2), there is discrimination or a disguised restriction on international trade. A level of risk is given by objective reality, and is determined in scientific fashion, whereas the level of protection (tolerated level of risk) is a policy target defined by the importing Member. Depending on the intrusiveness and restrictiveness of the measures taken by the importing Member, a level of protection can be anything from zero risk/high level of protection to medium to low, while the level of risk remains the same. Hence, the Panel's analysis seems to be directed at the wrong concept. Even if there are different levels of risk in comparable situations, that does not per se tell us anything about the respective levels of protection and about whether this difference deserves the label 'arbitrary' or 'unjustifiable'.

(Admittedly, when a Member adopts no measure in the face of a particular risk, then the (natural) level of risk translates directly into a level of protection or a tolerated level of risk. I am grateful to Lukasz Gruszczynski for highlighting this point to me. At the same time, the conceptual differences between level of risk and level of protection remain. A level of risk occurs naturally and a level of protection is a policy choice. Article 5.5 is about comparing these policy choices. So the Panel's 'test' cannot be the general test under (2)).

35 See, in particular, Panel Report, US-Poultry (China), para. 7.261. 
But the Panel seems to elevate scientific evidence, or lack thereof, into a generally applicable and exclusive tool for uncovering arbitrariness and unjustifiability. That, as Professor Regan points out, is conceptually wrong. The reason is simple. Two distinct measures can be perfectly justified in scientific terms, under Articles 2.2 and 5.1 , and yet each reflect a different level of protection. This difference in the level of protection may or may not be inconsistent with Article 5.5. This is because the choice of the level of protection is, at its heart, a risk-management choice - that is, the policy choice taken on the basis of a risk assessment. In this dichotomy, science is part only of risk assessment - in contrast, risk management is a policy choice of a non-scientific character. Hence, comparing two different levels of protection - each of which was set in a manner that is not conceptually determined by sciencecannot be a science-driven exercise either.

By way of a short example, assume that a risk assessment (a scientific study) has been performed that establishes that intake of (an otherwise very useful) substance $X$ in the amount of $Y$ over a period of $Z$ years creates a 1:100,000 risk of developing cancer. A risk manager will now be called upon to make the policy choice to determine the level of protection. What level of risk is tolerable for society? What should be the maximum legally permitted level of substance $X$ in a particular product and what should be the maximum resulting odds of developing cancer? Is $1: 100,000$ an acceptable level of risk? Or 1:10,000 or 1:1,000,000? How does one balance the usefulness of the product/substance against public-health concerns and human lives? This question is a non-scientific policy choice. Scientists are best placed to calculate the odds of developing cancer, but they are not better equipped than say, politicians, lawyers, economists, accountants, or carpenters on the issue of why regulation should establish a maximum risk level of 1:100,000 rather than 1:90,000.36

Assume now that parliament has promulgated a rule that implicitly accepts a risk level of 1:100,000 for substance $X$. Parliament has also previously regulated substance $S$, an entirely different substance, but with similar carcinogenic properties as substance $X$. For substance $S$, parliament has (implicitly or explicitly) decided that the maximum acceptable risk level is 1:130,000. Keep in mind that both pieces of legislation - for substance $X$ and substance $S$ - are based on a proper risk assessment that identifies the type of risk and quantifies it. Both pieces of legislation are therefore on a sound scientific footing and are consistent with Articles 2.2 and 5.1. It is just that in one instance (for substance $S$ ) parliament has been more risk averse than in the other instance (for substance $X$ ). As the Appellate Body has made clear, a difference of this sort may be perfectly normal and acceptable. '[G]overnments establish their appropriate levels of protection frequently on an ad hoc basis and over time', and therefore 'the goal set is not

36 See for instance Jan Bohanes (2002), 'Risk Regulation in WTO Law: A Procedure-Based Approach to the Precautionary Principle', 40:2 Columbia Journal of Transnational Law 323. 
absolute or perfect consistency [in levels of protection]'. ${ }^{37}$ 'It is only arbitrary or unjustifiable inconsistencies that are to be avoided'. But in this example, if both pieces of legislation are in and of themselves scientifically sound, how could science tell us whether the difference between the level of protection of 1:100,000 and $1: 130,000$ is 'arbitrary'? Plainly, this is a typical qualitative determination that may depend on a variety of factors, including the extent of the difference, the degree of similarity between the two scenarios regulated, the target groups protected by the legislation, the industrial usefulness of the substance involved, and a potentially endless list of further case-specific circumstances. The Panel's statements sit uncomfortably with what Article 5.5 is about.

The best way of reading the Panel Report is therefore to accept that the Panel was justified in considering, in this case, the absence of risk assessment for Section 727 as an indicator that the higher level of protection reflected in Section 727 was 'arbitrary' or 'unjustifiable', as compared to the level of protection of the PPIA. However, I fully agree with Professor Regan that the Panel inappropriately appears to imply that science should be the exclusive test for 'arbitrariness' and 'unjustifiability' under Article 5.5.

\section{Article $\mathrm{XX}(\mathrm{b})$ and its relationship to the SPS Agreement}

Finally, a few words on the Panel's finding under Article XX(b) and its relationship with the SPS Agreement. Professor Regan criticizes the Panel's findings and makes a series of interesting points. I have sympathy for his criticism and agree that the Panel leaves numerous questions unanswered, questions that Professor Regan identifies and discusses in meticulous fashion. At the same time, I find also the Panel's analysis not implausible ${ }^{38}$ and do not share all of Professor Regan's points of criticism. For instance, I am not certain why the word 'necessary' in Article XX (b) cannot encompass the requirement to ensure that a measure is based on a risk assessment or, for that matter, certain other (substantial) requirements of the SPS Agreement. ${ }^{39}$ Even if the ordinary meaning of 'necessary' does not include these

37 Appellate Body Report, EC Measures Concerning Meat and Meat Products (Hormones), WT/DS26/ AB/R, WT/DS48/AB/R, adopted 13 February 1998, DSR 1998:I, 135, para. 213.

38 Lukasz Gruszczynski also agrees with the outcome of the Panel's analysis, even if he criticizes the Panel's reasoning. Lukasz Gruszczynski (2011), 'United States: Certain Measures Affecting Imports of Poultry from China - Just Another SPS Case?', 2:3 European Journal of Risk Regulation, 431, 437.

39 See Professor Regan's article, Section 8. 'No amount of context can make the 'ordinary meaning' of the word 'necessary' in GATT XX(b) encompass, say, the requirement to do a risk assessment.' In my opinion, assessing whether a measure is 'necessary' includes considering the scientific justification of a measure. In demonstrating such scientific justification under Article XX(b), a WTO Member may rely on preexisting studies or may have to produce its own scientific study - which is also choice permissible under Article 5.1 of the SPS Agreement. Professor Regan also states that "[n]ecessary' refers to the relation that exists between the measure and its goal, whereas the SPS is about requiring specific techniques for investigating that relation.' I am not certain about how this distinction would play out in a dispute - the SPS Agreement does not necessarily require a WTO Member to perform a risk assessment (a Member can rely 
requirements - since the SPS Agreement declares that it 'elaborates' on Article XX (b), why can the SPS Agreement not be deemed something akin to-loosely speaking-an 'authentic interpretation' of that provision by the GATT/WTO membership, or, as Professor Regan suggests, to a special meaning of that term, within the meaning of Article 31.4 of the Vienna Convention? ${ }^{40}$ (However, in all fairness, this is not the interpretative methodological approach that the Panel took.) The word 'necessary' would then be (again loosely speaking) deemed to reflect the rules of the SPS Agreement, and ordinary meaning would cease to be the issue. There are plenty of deeming provisions in WTO law. ${ }^{41}$

Nevertheless, I also recognize that one could argue that Articles 2.4 and 3.2 demonstrate that, when the drafters wanted to create 'deeming' provisions, they did it expressly, which undermines the argument that the term 'necessary' should be deemed to encompass the SPS Agreement. More broadly, the term 'necessary' probably should also not include all aspects of the SPS Agreement-it does seem a stretch to argue that 'necessity' is elaborated by the obligation to create information points and to notify SPS measures to the SPS Committee prior to their enactment. ${ }^{42}$ The simple truth is that any definitive answer on this complex issue will necessarily be imperfect and leave some concerns unaddressed.

Beyond this admittedly somewhat agnostic statement, I would like to offer the following additional thoughts.

First, as Professor Regan himself states, the practical implications of the difference in the Panel's and Professor Regan's view are circumscribed. Even if Article $\mathrm{XX}(\mathrm{b})$ remains theoretically available to justify a GATT violation, the defending Member will still have to remove any inconsistency found to exist under the SPS Agreement. In other words, even if Article $\mathrm{XX}(\mathrm{b})$ remains theoretically available, and even if it does in a given case actually justify a GATT violation, this would not absolve the defending Member from bringing itself into compliance under the SPS Agreement. After all, the Panel did not seek to apply Article XX(b) to violations of the SPS Agreement.

Second, the Panel's finding is interesting for what it might imply for other questions. There is, for instance, the question I raised under Section 2, namely, whether an SPS measure must be challenged under the SPS Agreement (with or without the GATT 1994) or whether a complainant could be permitted to choose to claim only GATT 1994 violations. The Panel's approach of essentially fusing

on preexisting studies); it merely requires that a measure be demonstrably scientifically justified as assessed at the time of a dispute settlement proceeding. And, in my view, this is also what an important part of 'necessity' under Article XX(b) is about.

40 Prof. Regan's Article, footnote 53.

41 For instance, the Annex I-Illustrative List of Export Subsidies in the SCM Agreement contains subsidies that do not fit within the ordinary meaning of the definition of a subsidy in Article 1 - especially within the 'benefit' prong - but Annex I is a deeming provision, and that is enough.

42 See Annex B of the SPS Agreement. 
Article $\mathrm{XX}(\mathrm{b})$ and the SPS Agreement suggests to me that the Panel considers these two agreements as something akin to the inseparable package of rights and obligations' that the Appellate Body saw in Brazil-Desiccated Coconut in Article VI of the GATT and the SCM Agreement. ${ }^{43}$ Does this suggest that bringing a challenge against an SPS measure under the GATT alone is not an option? If Article $\mathrm{XX}(\mathrm{b})$ is fused and joined at the hip with the SPS Agreement such that a violation of the SPS Agreement precludes invoking Article $\mathrm{XX}(\mathrm{b})$, does it make sense to analyze an SPS measure under the GATT without considering it previously under the SPS Agreement?

Another tantalizing question is whether the Panel's reasoning betrays something on what that Panel thinks of the applicability of Article XX outside of the GATT - for instance, to the TBT Agreement. Unfortunately, I do not believe that the Panel Report tells us anything about that. First, as already noted, the USPoultry (China) Panel asks a different question - namely, whether Article XX(b) can justify a GATT violation, not a violation of the SPS Agreement. Second, there are numerous idiosyncrasies in the relationship between the GATT (and Article XX (b)) and the SPS Agreement that militate against transferring the Panel's analysis to, say, the relationship between Article XX and the TBT Agreement. These idiosyncrasies are, most importantly, the specific language in the SPS Agreement (namely, that the SPS Agreement 'elaborates' on Article $\mathrm{XX}(\mathrm{b})$ ), the safe-haven clauses under Articles 2.4 and 3.2, and to some degree also the fact that Article XX (b) is a defense whereas the SPS Agreement contains primary obligations.

43 Appellate Body Report, Brazil-Measures Affecting Desiccated Coconut, WT/DS22/AB/R, adopted 20 March 1997, DSR 1997:I, 167, p. 14 (quoting with approval the statement of the Panel in that dispute). 